\title{
Caso Clínico Radiológico Adulto
}

EDUARDO SABBAGH P.*, MAURICIO SALINAS F.*, MARIANA KAHN CH.*, HUGO VALENZUELA C.* y DAVID LAZO P.*

\section{Historia clínica}

Mujer de 67 años de edad, sin antecedentes mórbidos de importancia que ingresa por un cuadro de 5 semanas de evolución caracterizado por dorsalgia, tos, disnea y compromiso del estado general progresivos, asociados a baja de peso. Una semana previa a la consulta, inicia hemoptisis de moderada cuantía.

Destaca al ingreso una abolición del murmullo pulmonar en el tercio basal del hemitórax derecho.

Se efectuó radiografía $(\mathrm{Rx})$ de tórax que se muestra en la Figura 1.

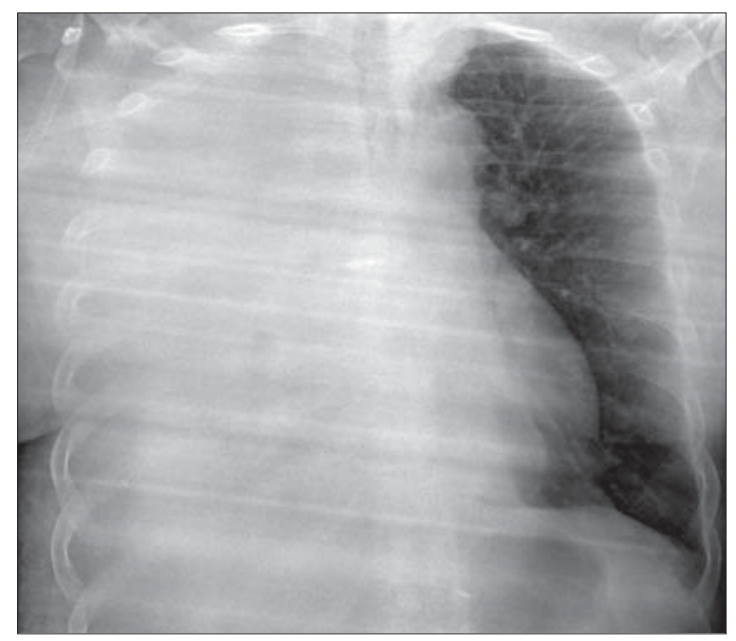

Figura 1. Rx de tórax simple.

Describa y comente el diagnóstico diferencial.

* Servicio de Radiología y Médico-Quirúrgico Respiratorio. Instituto Nacional del Tórax. Santiago. 


\section{Descripción Rx de tórax simple:}

La Rx de tórax pósteroanterior (Figura 1), demuestra opacificación completa del hemitórax derecho, con discreto desplazamiento del mediastino hacia el lado izquierdo. La columna aérea de la tráquea está conservada, pero no se distingue claramente el sistema bronquial derecho. Pulmón y pleura izquierda, sin alteraciones significativas.

\section{Comentario}

El hallazgo de opacificación completa de un hemitórax puede tener varias causas:

1. Neumonectomía.

2. Patología pleural:

- Derrame masivo.

- Neoplasia primaria o secundaria.

3. Condensación pulmonar.

4. Atelectasia pulmonar.

5. Neoplasia pulmonar.

6. Combinación de las anteriores.

Lo habitual es que se trate de una combinación de estas causas. Por ejemplo: neumonectomía, con ocupación parcial de la cavidad residual por derrame. Condensación neumónica, con empiema asociado. Neoplasia pleural o pulmonar con derrame asociado. Neoplasia pulmonar con atelectasia y/o neumonía post obstructiva, con o sin derrame asociado, etc.

Por supuesto frente a la opacificación unilateral en la radiografía del tórax, se debe solicitar una tomografía computada, con contraste endovenoso y posteriormente una fibrobroncoscopía. Pero hay varios signos en la radiografía que nos permiten plantear hipótesis diagnósticas:

a. En casos de neumonectomías y atelectasias, se acompaña de amputación del bronquio fuente y notorio desplazamiento del mediastino hacia el lado ipsilateral. Si se agrega derrame, este desplazamiento es menor o inexistente, dependiendo de la cuantía del derrame.

b. Cuando hay condensación parenquimatosa, los bronquios están permeables, apareciendo el fenómeno de broncograma aéreo y el mediastino permanece centrado. Sin embargo, si se agrega derrame, el mediastino puede estar desplazado hacia el lado contralateral.

c. En una neoplasia pleural benigna, con o sin derrame, el mediastino será desplazado hacia el lado contralateral.

d. En las neoplasias malignas de la pleura ya sea primarias (mesotelioma) o secundarias (metástasis de adenocarcinoma), con o sin de- rrame, característicamente se produce disminución de volumen del hemitórax, con disminución de la caja torácica, elevación del hemidiafragma y desplazamiento del mediastino.

e. En una neoplasia pulmonar, dependerá si el proceso es periférico o central, comprometiendo o no a los bronquios centrales.

- Si es periférico, se comporta como neoplasia pleural.

- Si es central con compromiso bronquial, se puede acompañar ya sea de atelectasia del pulmón, con desviación del mediastino hacia el lado ipsilateral, a no ser que se acompañe de derrame importante, donde incluso puede ser desplazado hacia el lado contralateral. Si se acompaña de neumonía post obstructiva, no se desvía el mediastino. Sin embargo, si hay derrame asociado, puede desplazarse hacia el lado contralateral.

También puede ocurrir, que una parte del pulmón presente neumonía post obstructiva y otra presente atelectasia, pudiendo así, desplazarse hacia el lado ipsilateral. Obviamente ambas situaciones, neumonía post obstructiva y atelectasia de una porción, con derrame, se desplazará hacia contralateral.

Nuestra paciente, presenta opacificación, con discreto desplazamiento contralateral del mediastino, y mala visibilidad del bronquio derecho. Esto significa que probablemente exista una neoplasia central, con neumonía post obstructiva y/o derrame discreto, o atelectasia, con derrame abundante o atelectasia con neumonía post obstructiva y derrame moderado.

Se practicó una tomografía computada cuyas principales imágenes se muestran en las Figuras 2 y 3.

\section{Descripción de los cortes tomográficos}

Los cortes coronales (Figuras $2 \mathrm{a}$ y $2 \mathrm{~b}$ ) y axiales (Figuras $3 a$ y $3 b$ ) de tomografía computada, demuestran una masa central derecha, que obstruye por completo al bronquio lobar superior derecho, al lobar medio y al lobar inferior y estrecha al bronquio principal e intermedio. El pulmón esta atelectásico y hay abundante derrame, responsable del discreto desplazamiento mediastínico contralateral.

\section{Hallazgos anátomo-patológicos}

La fibrobroncoscopía demostró que la mucosa del bronquio intermedio estaba engrosada y era irregular, estrechando el lumen del bron- 

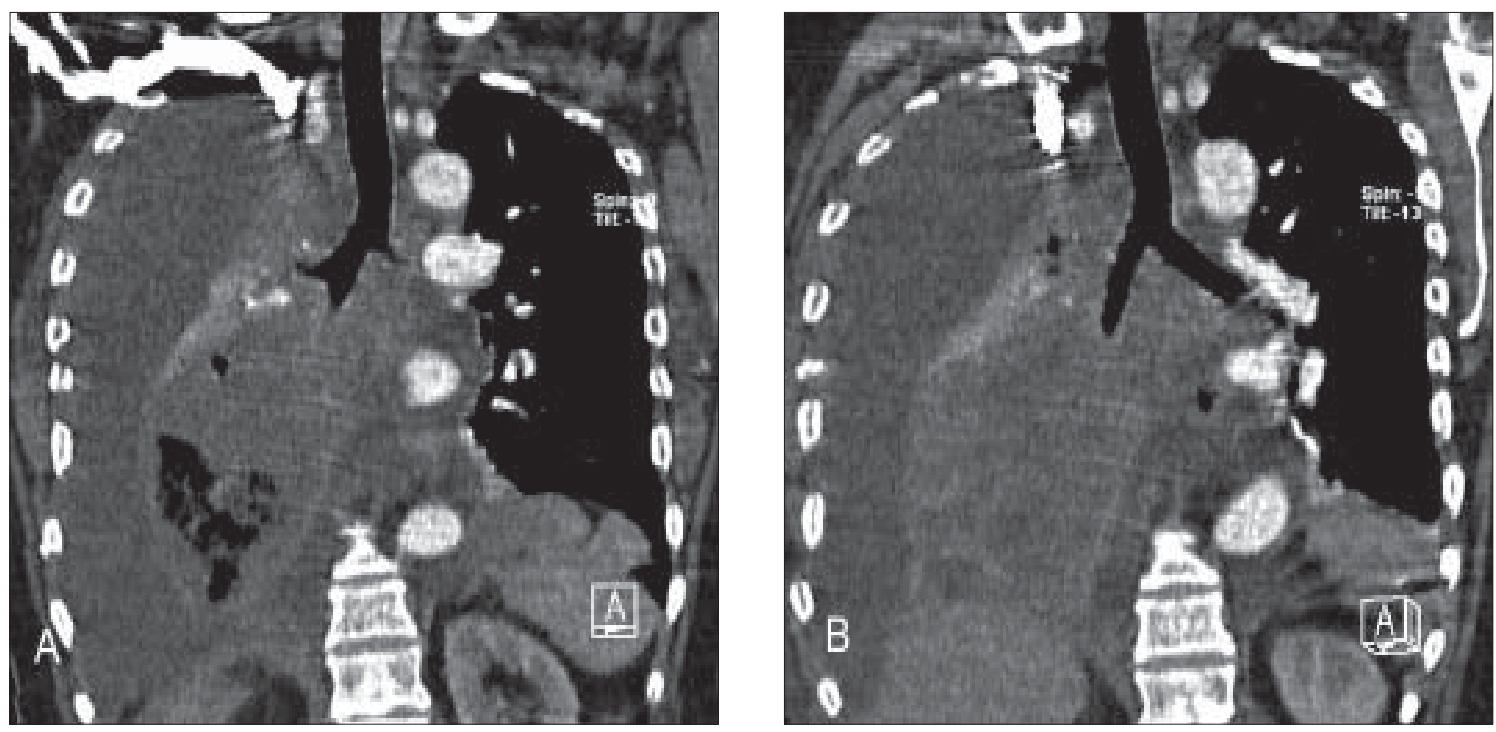

Figura 2. Tomografía computada, reconstrucciones coronales 1 (Figura 2a) y 2 (Figura 2b).
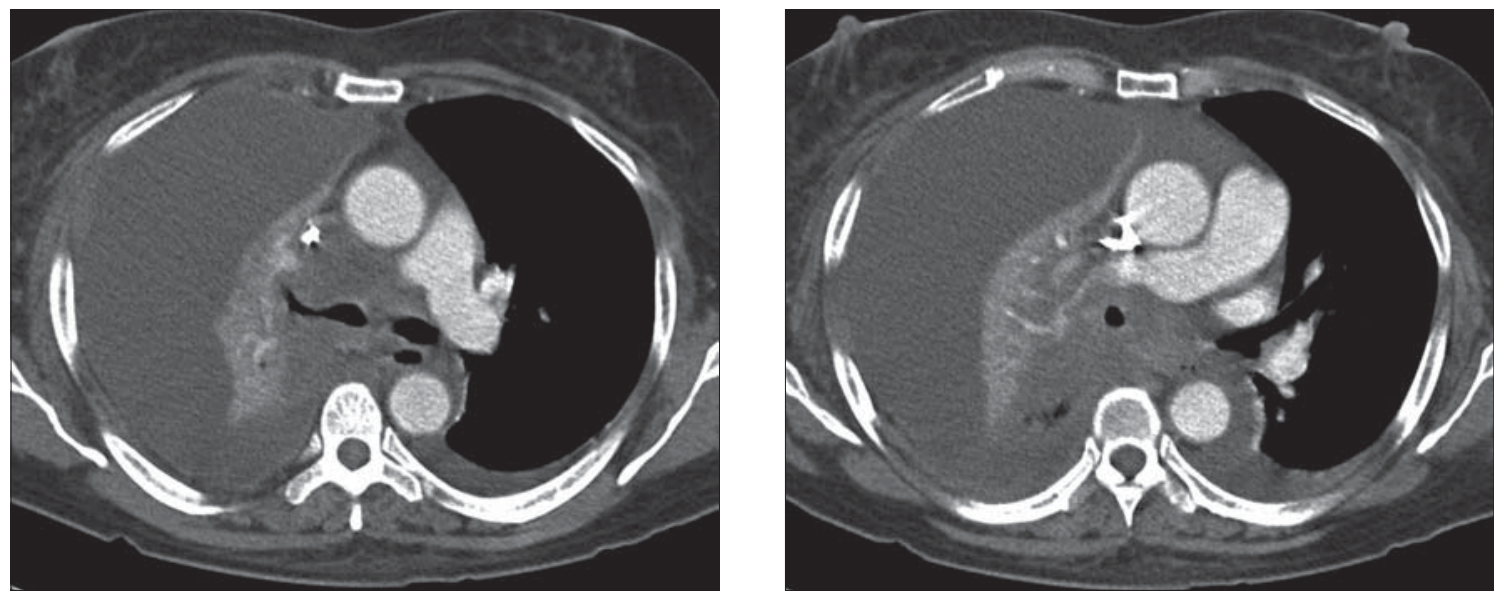

Figura 3. Tomografía computada, cortes axiales 1 (Figura 3a) y 2 (Figura 3b).

quio intermedio y obstruyendo el lumen del bronquio lobar medio y bronquio lobar inferior derecho. La biopsia bronquial confirmó un adenocarcinoma de células grandes pobremente diferenciado.

\section{Referencias}

1.- MÜLLER N L, FRASER R S, COLMAN N C, PARE $P$ D. Radiologic Diagnosis of Diseases of the Chest.
WB Saunders Company. Philadelphia, USA 2001.

2.- ROSADO-DE-CHRISTENSON M L, TEMPLETON P A, MORAN C A. Bronchogenic carcinoma: radiologicpathologic correlation. Radiographics 1994; 14: 429-46.

3.- FERRER J, ROLDÁN J, TEIXIDOR J, PALLISA E, GICH I, MORELL F. Predictors of pleural malignancy in patients with pleural effusion undergoing thoracoscopy. Chest 2005; 127: 1017-22.

4.- GURNEY J W. Atypical manifestations of pulmonary atelectasis. J Thorac Imaging 1996; 11: 165-75.

\section{Correspondencia a:}

Dr. Eduardo Sabbagh P.

Instituto Nacional del Tórax, Santiago, Chile.

E-mail: edo.sabbagh.p@ivtr.net 